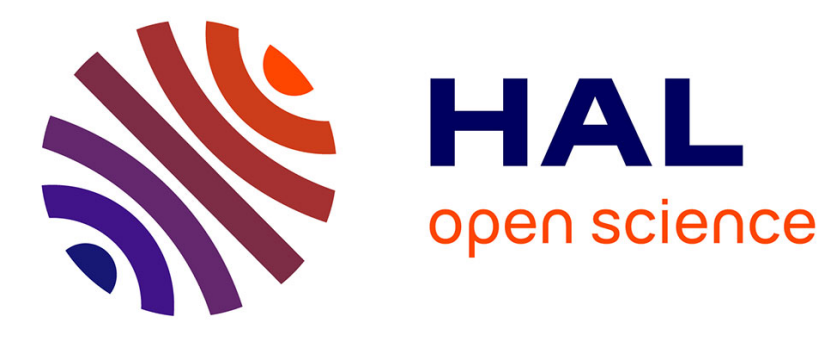

\title{
Comprehension of chip formation in laser assisted machining
}

Guénaël Germain, Philippe Dal Santo, Jean-Lou Lebrun

\section{To cite this version:}

Guénaël Germain, Philippe Dal Santo, Jean-Lou Lebrun. Comprehension of chip formation in laser assisted machining. International Journal of Machine Tools and Manufacture, 2011, 51 (3), pp.230-238. 10.1016/j.ijmachtools.2010.11.006 . hal-01068075

\section{HAL Id: hal-01068075 \\ https://hal.science/hal-01068075}

Submitted on 24 Sep 2014

HAL is a multi-disciplinary open access archive for the deposit and dissemination of scientific research documents, whether they are published or not. The documents may come from teaching and research institutions in France or abroad, or from public or private research centers.
L'archive ouverte pluridisciplinaire HAL, est destinée au dépôt et à la diffusion de documents scientifiques de niveau recherche, publiés ou non, émanant des établissements d'enseignement et de recherche français ou étrangers, des laboratoires publics ou privés. 


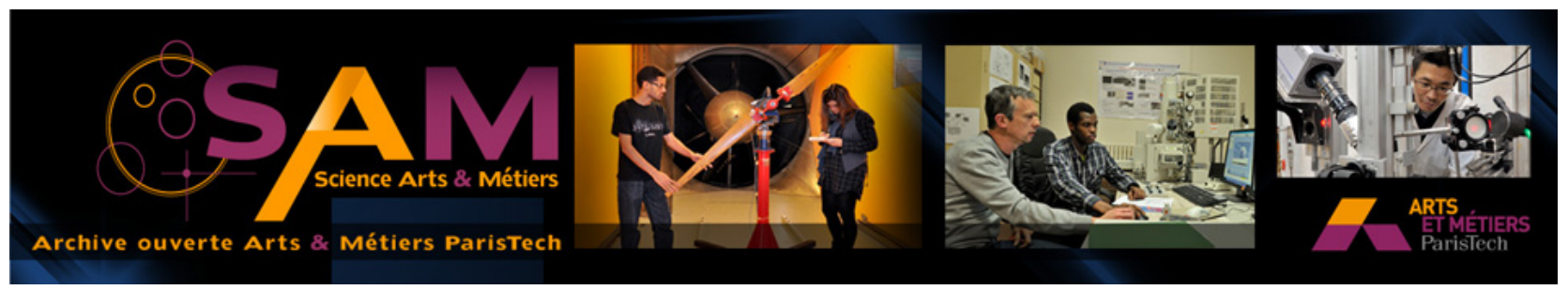

Science Arts \& Métiers (SAM)

is an open access repository that collects the work of Arts et Métiers ParisTech researchers and makes it freely available over the web where possible.

This is an author-deposited version published in: http://sam.ensam.eu

Handle ID: .http://hdl.handle.net/10985/8606

\section{To cite this version :}

Guénaël GERMAIN, Philippe DAL SANTO, Jean-Lou LEBRUN - Comprehension of chip formation in laser assisted machining - International Journal of Machine Tools and Manufacture Vol. 51, n³, p.230-238 - 2011 


\title{
Comprehension of chip formation in laser assisted machining
}

\author{
G. Germain*, P. Dal Santo, J.L. Lebrun \\ Arts et Métiers ParisTech, LAMPA-EA1427, 2, Bd de Ronceray 49000 Angers, France
}

\begin{abstract}
A B S T R A C T
Laser Assisted Machining (LAM) improves the machinability of materials by locally heating the workpiece just prior to cutting. Experimental investigations have confirmed that the cutting force can be decreased, by as much as $40 \%$, for various materials. In order to understand the effect of the laser on chip formation and on the temperature fields in the different deformation zones, thermo-mechanical simulations were undertaken. A thermo-mechanical model for chip formation was also undertaken. Experimental tests for the orthogonal cutting of $42 \mathrm{CrMo} 4$ steel were used to validate the simulation. The temperature fields allow us to explain the reduction in the cutting force and the resulting residual stress fields in the workpiece.
\end{abstract}

Keywords:

LAM

Chip formation

FEM

Cutting force

Residual stresses

\section{Introduction}

The use of high strength materials, like titanium alloys and tool steels, is becoming increasingly common in industry. However, these materials are difficult to machine because they maintain their mechanical properties even at high temperatures. Conventional machining of these materials is slow and inefficient, because only slow cutting speeds can be used. In order to increase productivity certain types of 'assistance' can be used to facilitate the cut, for example, high pressure ultrasonic assistance or assistance by locally heating, water jet assistance and cryogenic assistance, to name a few. The idea of hot machining began with the following processes: heating of the workpiece in a furnace, induction heating and/or electrical arc heating. But these processes did not give good results, because the power density was insufficient to be effective. In the sixties and seventies, electrical resistance heating between the tool and the workpiece was investigated. An electric current of several hundred amps made it possible to decrease the cutting force of approximately $10 \%$ in steels [1]. In the seventies and eighties, plasma heating was developed. An increase in tool life and productivity was noted [2]. Also in the eighties, $\mathrm{CO}_{2}$ laser heating was tested, an improvement in the workability of several materials was noted. However, the cost of installing a $\mathrm{CO}_{2}$ laser on a production scale is a significant barrier to the development of this process. Nowadays, because new, economic, easy and transportable laser sources, like diode lasers and Nd:YAG lasers are available, there is increased interest in Laser Assisted Machining (LAM).

\footnotetext{
* Corresponding author. Tel.: +33 241207 343; fax: +33 241207320.

E-mail address: guenael.germain@ensam.eu (G. Germain).
}

LAM will only become viable on an industrial scale if it can be proved versatile in different domains of activity. It has already been shown that LAM makes it possible to machine high strength metals like Ti6Al4V [3,4], Inconel 718 [5], graphite iron [6], AISI D2 tool steel [7] or metal matrix composites [8] and ceramics [9-11]. For these materials, it improves workability by decreasing the cutting forces and by increasing the tool life. LAM is the only process with which it is possible to machine very hard materials. In addition, LAM can also increase the productivity when machining traditional or less hard materials. The cutting parameters (depth, speed, etc.) can be increased while improving the surface integrity of the part (surface quality, residual stresses). Moreover, machining is carried out dry, which allows cost reductions concerning the purchase and the treatment of lubricants and makes the process more environmental friendly. LAM can also increase the number of operations possible with the same machine. For example, a laser equipped lathe is able to carry out laser deburring and thermal surface treatments.

Optimization of the LAM process depends heavily on the control of laser heating. The laser heating must be extremely intense in order to affect the cutting process. But in this case, it can cause unwanted effects (thermal expansion of the workpiece, melting of the surface, etc). The goal of this paper is to propose a numerical approach to model laser assisted machining and highlight the effects of laser heating on the cutting zone.

\subsection{Principle of LAM}

LAM is a high temperature cutting process using a laser beam as the heat source (Fig. 1). The laser is used as an intense heat source to 


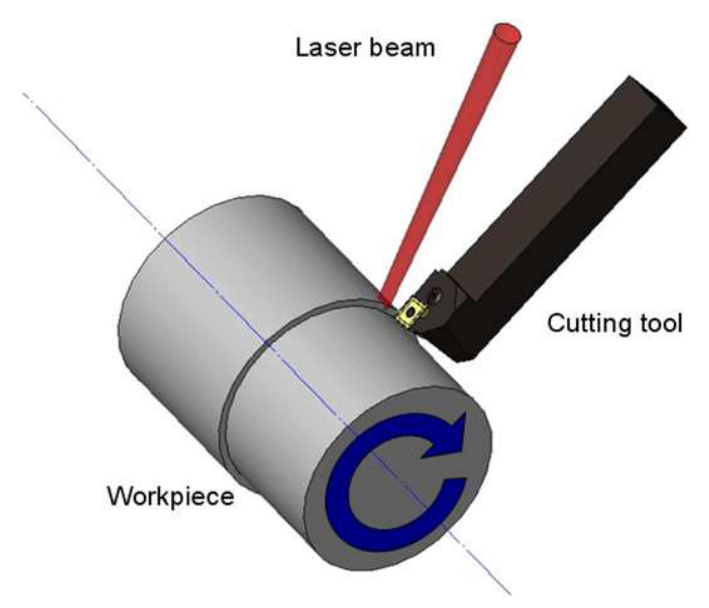

Fig. 1. LAM configuration (for a turning operation).

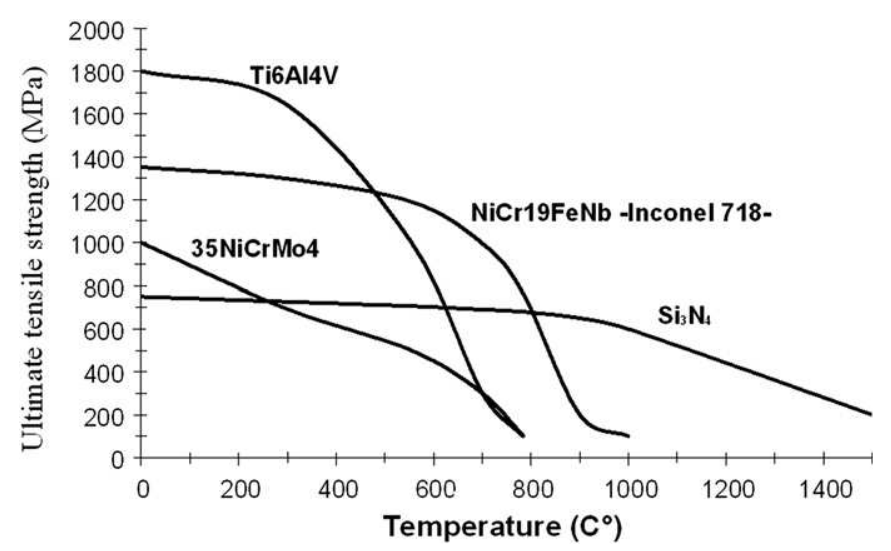

Fig. 2. The Ultimate Tensile Strength $\left(\sigma_{\mathrm{UTS}}\right)$ of various materials as a function of temperature [3].

decrease the strength of the machined material just prior the cut, without melting or sublimation of the workpiece.

The principle of the process is to reduce the cutting force necessary to machine the material by increasing the temperature to the point where the strength of the material is reduced (Fig. 2). Indeed at high temperature, the specific cutting energy is weak, which improves workability. Fig. 2 shows the characteristic evolution of the ultimate tensile strength of various materials with regard to temperature [3].

For a large number of materials a drop in the tensile strength or hardness occurs between 500 and $600{ }^{\circ} \mathrm{C}$. To be effective the cutting tool must thus operate in the zone where the temperature remains higher than this value. However, the distance between the tool and the laser spot must be sufficient to prevent degradation of the tool due to the high temperature. A major feature of this process is the number of parameters that must be controlled during the cutting operation. In addition to the usual cutting parameters (cutting speed, feed rate, depth of cut and type of tool), there are the laser parameters (laser power, the angles of incidence and the diameter of the laser spot) and also interaction parameters between the laser beam and the cut (i.e. the position of the laser relative to the tool). The effect of the angle of incidence has been investigated by Germain et al. [12]. In particular, it has been shown that the laser beam absorption is the same for all angles of incidence less than $40^{\circ}$ from the surface normal. The angle of incidence used for all of the work reported in this article is $20^{\circ}$. This value was chosen in order to facilitate the tests (i e. to prevent the laser nozzle from hitting the tool).

\subsection{Experimental equipment}

A numerically controlled lathe (REALMECA RT-5) equipped with a $2.5 \mathrm{~kW}$ Nd:YAG laser was used in this work. The laser nozzle can be controlled using three translations and two rotations. A Numerical Control System (NUM 1060) allows the control of the seven independent degrees of freedom. The high-power laser beam is delivered through a fiber optic cable to the lathe chamber, where it is focused on the workpiece surface. During machining, a gas under pressure (air) is forced through the laser nozzle to protect the focusing lens from being damaged by chips. Three components of the cutting force are measured by a Kistler piezoelectric dynamometer. The output signals for the cutting force are amplified and collected by a data acquisition system with the LabView $\mathbb{R}$ software.

\subsection{Literature review of analytical solutions for the modelling of laser heating and LAM}

As discussed by Chen [13] when considering only the laser heating, the temperature field can be determined by solving the heat equation. The analytical solution to calculate the temperature distribution in the workpiece resulting from a heat source with a Gaussian power distribution in motion has been reported by Chen. This equation developed is shown in Eq. (1). In this analytical model, the movement consists of a translation in the $x$-direction with a constant speed of $V_{x}$. The heat source is switched on at time, $t=0$ and off at $t=\tau$. Heat transfer via radiation and convection are neglected. The laser beam is located at the origin at time $t=0 \mathrm{~s}$. The thermo-physical properties ( $\alpha$ and $k$ ) are assumed to be independent of temperature.

$T(x, y, z, t)=T_{0}+\frac{8 P_{a} \sqrt{\alpha}}{k \cdot \pi^{3 / 2}} \int_{\sqrt{t-\tau}}^{\sqrt{t}} \frac{\exp \left[-4 \cdot \frac{\left[x-V_{x}\left(t-u^{2}\right)\right]^{2}+y^{2}}{d^{2}+16 \alpha u^{2}}-\frac{z^{2}}{4 \alpha u^{2}}\right]}{d^{2}+16 \alpha u^{2}} d u$

where $T_{0}$ is the initial temperature, $\alpha$ is the thermal diffusivity, $P_{a}$ is the absorbed laser power, $k$ is the coefficient of conduction, $d$ is the diameter of the laser beam, $V_{x}$ is the speed of the laser beam in the $X$-axis direction.

This solution is very general but it can be optimized for the LAM process. Analytical studies of laser heating in terms of LAM have been conducted at the University of Purdue by Rozzi et al. [14,15]. They determined the temperature field (3D) induced by a laser beam in a bar of silicon nitride in motion. Their model considers the laser beam moving in both axial and circumferential directions (Fig. 3). Natural and forced convection around the laser spot by the air stream used to protect the laser head are considered. The thermo-physical parameters of the workpiece are assumed to be independent of the temperature. Radiation is neglected.

The authors report that this model gives correct values for the temperature field. The temperature in the tool increases with the laser power and with the reduction of the laser beam diameter. Axial conduction in the workpiece is more important when the feed rate of the laser beam is low. The heated depth diminishes with increasing speed of rotation of the workpiece. In addition, the authors conclude that natural convection can be neglected. By contrast, the forced convection around the laser spot by the air stream must be considered.

This model has been further enriched by Rozzi et al. [16] to take into account the heat generated in the primary shear zone, the changing geometry of the workpiece during machining and 


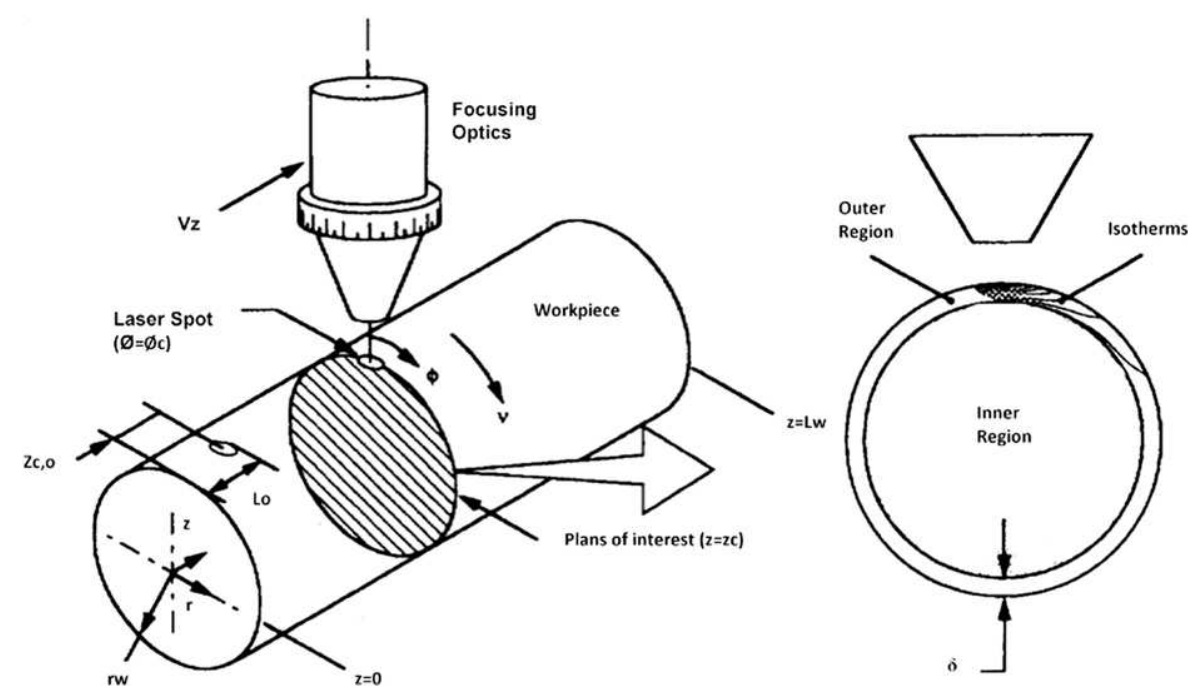

Fig. 3. Description of the analytical model developed by Rozzi et al. [15].

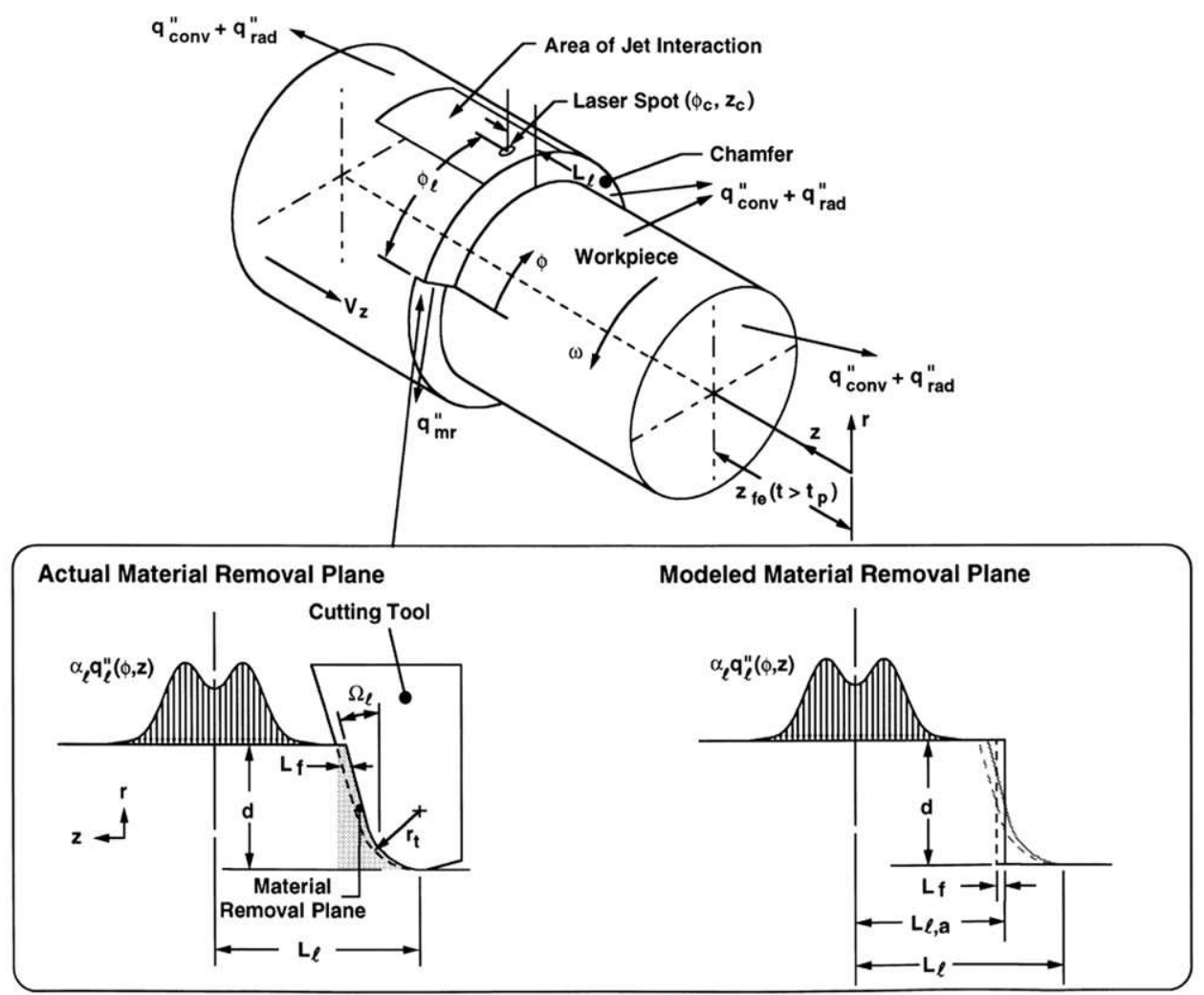

Fig. 4. Description of the enriched model developed by Rozzi et al. [16].

preheating of the material (Fig. 4). The results of this new model have been detailed for various process configurations [16].

In a further publication, Rossi et al. [17] note that heat generation in the primary cutting zone greatly increases the surface temperature at the location of the cut. This result brings into question the conclusion of their first model [14,15], which predicted a sharp drop in temperature with an increase in the rotational speed of the workpiece. Indeed, if the speed increases, the heat input due to the laser decreases, but the heat generated in the primary zone increases. With this in mind, the reduction in temperature at the tool as the rotating speed increases is much lower than that obtained by their first model. However, the depth of the heated material is still lower at high speed.

This model was subsequently adapted by P.A. Rebro et al. for machining mullite [5] and by F. E. Pfefferkorn [9] for establishing a heat model of semi-transparent ceramics under LAM. The model helps to estimate the temperature with respect to the different process parameters, to optimize the power and to avoid cracks formation during the machining of ceramics. It provides an understanding of the phenomena, including the role of various parameters on the temperature field. However, in order to understand the role of heating on the various zones (i.e. the primary shear zone) 
which are important in terms of chip formation the analytical approach of Rossi et al. is inadequate and an alternative approach must be studied. Hence, in this work, numerical modelling of LAM has been carried out using the finite element method to study the influence of laser heating of the material just prior to cutting.

\section{Modelling procedure}

The goal of this paper is to propose a numerical model, based on the finite element method, which is suitable for the study of LAM. This is necessary because the analytical models discussed above do not take into account the thermo-mechanical non-linearity's that occur in the cutting zone during chip formation. The LAM process simulation is conducted in two steps. Firstly, a purely thermal simulation of laser heating is undertaken and secondly a coupled thermomechanical simulation of the cutting process is completed. The temperature field resulting from the laser heating is the initial temperature field for the simulation of the cutting process.

\subsection{Numerical model of the laser heating}

In order to model the heat input due to the laser, a thermal flux was imposed on the workpiece over a zone corresponding to the surface of the laser spot. The thermal flux is displaced at the cutting speed and its intensity corresponds to the power absorbed by the material. During laser irradiation of the workpiece, only a small part of the laser beam energy is really absorbed by the material as the greater part is reflected. As a consequence the heat flux imposed in the numerical simulation as a loading condition must be the absorbed flux entering the part and not the total flux of the laser beam. The absorption coefficient represents the fraction of the absorbed power compared to the emitted power. This coefficient depends on many parameters such as the laser wavelength, the workpiece material, surface roughness, surface temperature, etc. The coefficient of absorption used in the simulation was determined by comparing numerical and experimental results.

To this end a numerical model was developed in order to determine the coefficient of absorption. This was done with the commercial finite element package Abaqus/Standard $®$. A fortran subroutine was developed in order to apply and move the thermal flux along the top surface of the workpiece (Fig. 5), as a function of time. The laser beam was modelled as a surface heat flux with a Gaussian distribution and was applied over a surface whose diameter corresponds to the spot size $(0.8 \mathrm{~mm})$. The material properties necessary to resolve the problem include: the density, the thermal conductivity and the specific heat, all of which are dependent on temperature, in a range from 0 to $1150{ }^{\circ} \mathrm{C}$. The latent heat of fusion has been introduced by artificially increasing the specific heat at the melting temperature of the material.

The finite element mesh was composed of 8-noded linear heat transfer bricks. A plane of symmetry was exploited so that, only half of the workpiece was modelled. The dimensions of the workpiece modelled were $20 \times 2.5 \times 1 \mathrm{~mm}^{3}$. The initial temperature was $20{ }^{\circ} \mathrm{C}$. The bottom face of the workpiece was maintained at $20^{\circ} \mathrm{C}$ at all times. Numerical simulations were conducted with various laser powers and two laser displacement rates of 0.5 and $1 \mathrm{~m} \mathrm{~s}^{-1}$. These were the same as the experimental test which were carried out on a $42 \mathrm{CrMo} 4$ steel with seven laser powers $(500,750,1000$, $1250,1500,1750$ and $2000 \mathrm{~W}$ ) and two displacement rates ( 0.5 and $1 \mathrm{~m} \mathrm{~s}^{-1}$ ). For each test the depth and the width of the molten zone were carefully measured. The absorption coefficient was determined by minimizing the differences between the simulated and the experimental molten pool volume (Fig. 6). The absorption coefficient was found to be effectively independent of the emitted laser power. Absorption coefficients of 0.26 and 0.27 where determined for displacement rates of 0.5 and $1 \mathrm{~m} \mathrm{~s}^{-1}$, respectively. Fig. 6 shows a relatively good correlation between the numerical and experimental results concerning the prediction of the volume of the melted zone.

The volume of the melted zone was chosen as a criterion for comparison because it reflects the energy absorbed by the material. However, the absorption of molten metal is different from that of the same non-molten metal, which creates an error when determining the absorption coefficient in this way. Never-the-less, this error is considered to be low because the tests discussed above result in a relatively small melted volume of material (i.e. the temperature is only slightly above the melting temperature).

The simulations appear to predict a molten volume with a slightly larger depth and a smaller width than the experimentally

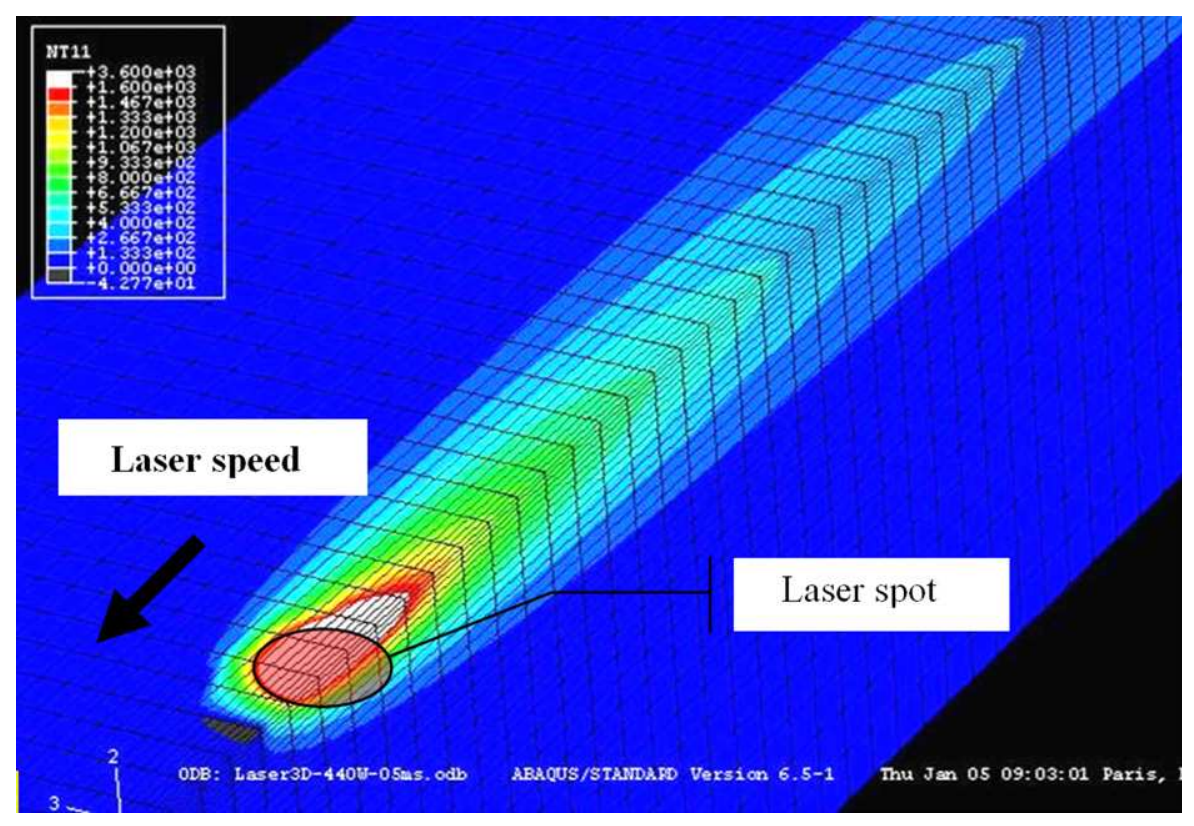

Fig. 5. The temperature distribution resulting from laser heating ( $440 \mathrm{~W}$ at $0.5 \mathrm{~m} \mathrm{~s}^{-1}$ ). 
determined molten volume. Fig. 7 shows the 2D geometry of the calculated and experimental melted areas on the same scale, for a laser power of $1500 \mathrm{~W}$ and a displacement rate of $0.5 \mathrm{~m} \mathrm{~s}^{-1}$. This difference is due to convection, conduction, Lorentz forces and surface tension (Marangoni flows) not taken into account in the numerical modelling. These phenomena induce movement in the melt which strongly influence the molten pool shape [18].

\subsection{Thermo mechanical model of the cut}

As discussed in Section 2 above, the second part of the numerical modelling procedure is to undertake a coupled thermo-mechanical simulation of the cutting process, using the temperature field resulting from the laser heating as the initial temperature field.

This was also done using the commercial finite element package Abaqus $\AA$. Two-dimensional models were built assuming conditions of plane strain. The dimensions of the workpiece were $2.5 \times 1.6 \times 1 \mathrm{~mm}^{3}$. The workpiece was considered to be deformable and the lower face of the model was fixed (i.e. all displacements were set to zero). A temperature of $20^{\circ} \mathrm{C}$ was imposed on this face.

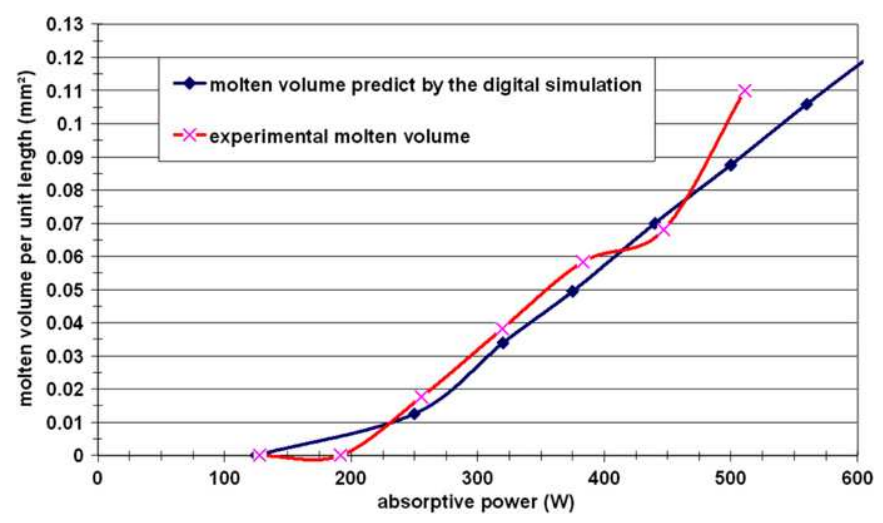

Fig. 6. Comparison between the experimentally and numerically determined molten volumes $\left(0.5 \mathrm{~m} \mathrm{~s}^{-1}\right)$.
Neither free, nor forced convection at the workpiece surface was taken into account.

The plastic material behaviour of the $42 \mathrm{CrMo} 4$ steel was modelled using the temperature dependent Johnson-Cook law [19]. This behaviour law is a function of the temperature, the strain and the strain rate. The material properties used in the models are shown in Table 1.

The model was composed of predominately four node quadrilateral elements (CPE4RT) with coupled temperature-displacement degrees of freedom. Triangular elements (CPE3T) were also used on the lower part of the workpiece in order to increase the element size. The mesh contained 3272 elements. The approximate element size in the cutting zone is $10 \mu \mathrm{m}$. The tool was considered to be rigid with the same geometry as that used in the experimental work. The contact between the tool and the workpiece was modelled using a kinematic formulation with a constant Coulomb type friction coefficient of 0.1 . The cutting speed was applied at the tool and the feed rate was considered to be negligible when compared to the cutting speed. A node separation criterion was not used to model the cut. In order to avoid premature distortion of the mesh an Arbitrary Lagrangian Eulerian formulation was applied to the elements of the workpiece. The formation of the chip occurs naturally via the rearrangement of the mesh. Re-meshing is not necessary in order to achieve the desired displacement.

\subsection{Validation of the numerical model of the cut}

The thermo-mechanical model has been validated by experimental orthogonal cutting tests. The tests are carried out on disks with a thickness, $w$, of $1 \mathrm{~mm}$ (Fig. 8).

The cutting tool consisted of a CFIR2525 M06 tool holder with LCGN 160202 0600FG CP500 inserts from SECO. Three different cutting speeds were investigated $\left(V c=1,2\right.$ and $\left.4 \mathrm{~m} \mathrm{~s}^{-1}\right)$ with a cutting depth (or feed) of $a=0.1 \mathrm{~mm}$ for the $42 \mathrm{CrMo}_{4}$ steel. For LAM, the laser power was fixed at $1000 \mathrm{~W}$ and the tool was placed $3 \mathrm{~mm}$ behind the laser beam. The calculated tangential cutting force was compared to the experimentally determined one. Fig. 9 shows the results for (a) Conventional Machining (CM) and (b) LAM

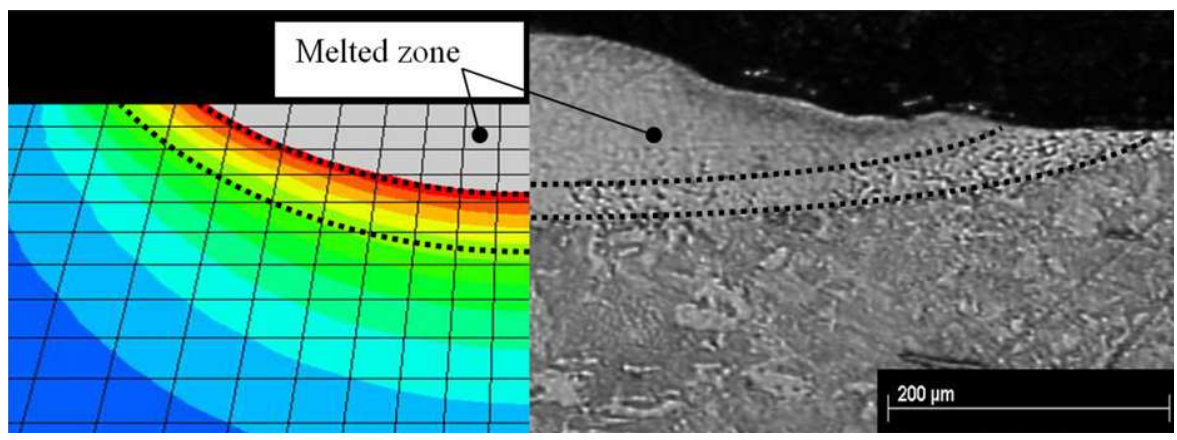

Fig. 7. Comparison between the geometry of the numerical and experimental thermally affected zone for a $1500 \mathrm{~W}$ laser power and a displacement rate of $0.5 \mathrm{~m} \mathrm{~s}{ }^{-1}$.

Table 1

Material characteristics used for thermo mechanical model of the cut.

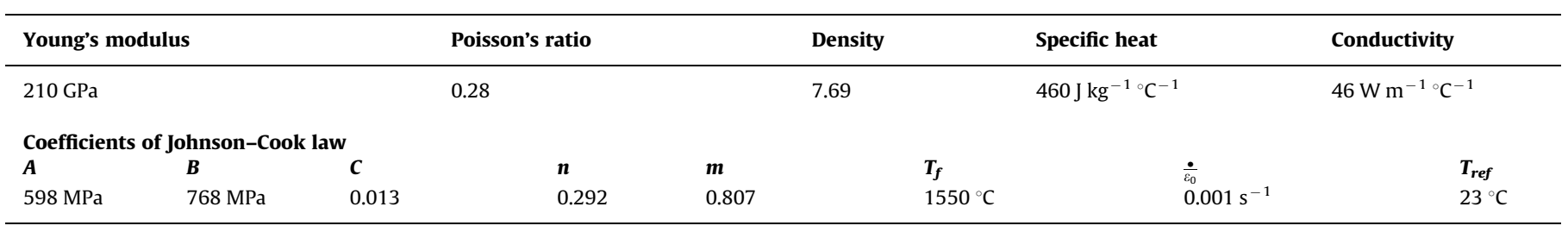



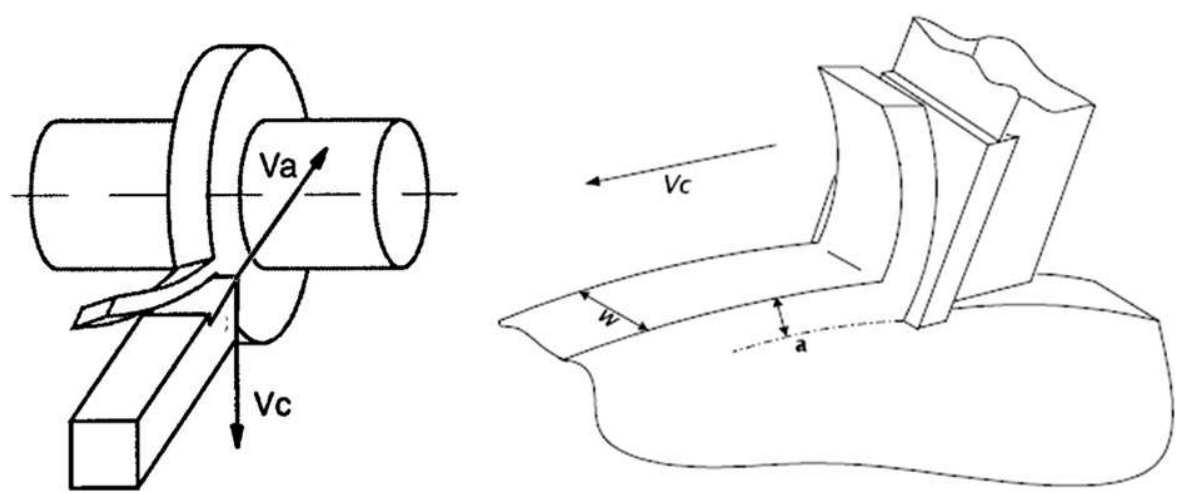

Fig. 8. Principle of orthogonal cutting.

a

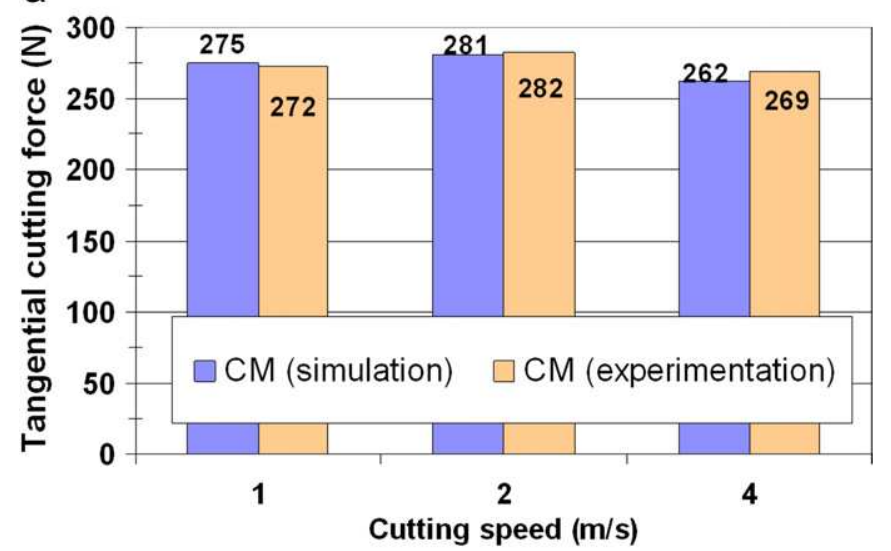

b

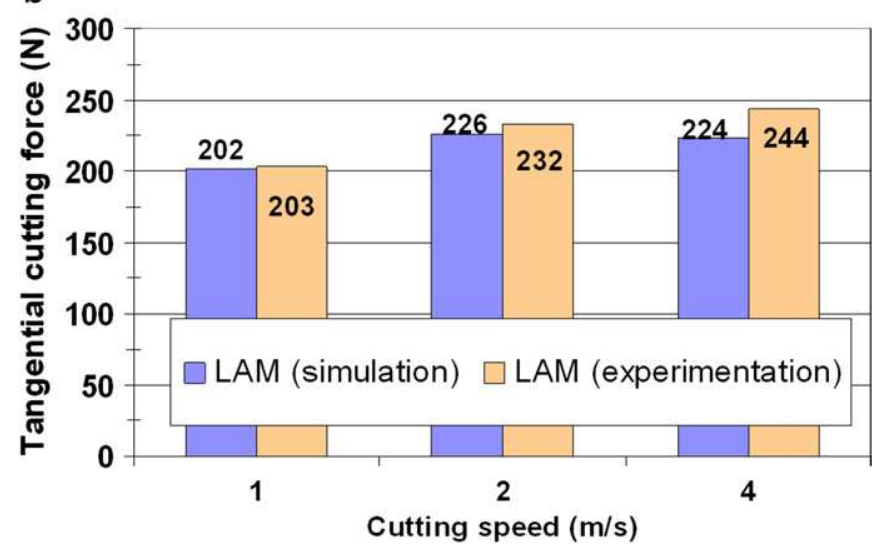

Fig. 9. Comparison between the calculated and experimentally determined tangential cutting forces for different cutting conditions: (a) conventional machining and (b) LAM.

as a function of the cutting speed. It can be seen that the numerical predictions are good. Laser assistance results in a reduction of the cutting force by $34 \%, 21 \%$ and $10 \%$, respectively, compared to conventional machining for the three cutting speeds investigated.

The chips obtained experimentally via orthogonal cutting are continuous and correspond in general to the chip form generated via the numerical simulation. The good agreement between the experimental and numerical values validates the numerical model of the LAM process, at least for the cutting configuration studied (orthogonal cutting, steel $42 \mathrm{CrMo}_{4}, a=0.1 \mathrm{~mm}$ and $1<\mathrm{Vc}<4 \mathrm{~m} \mathrm{~s}^{-1}$ ).

\section{Influence of the cutting speed in LAM on the temperature field}

The maximum calculated temperatures at the laser spot are approximately 1346,954 and $680^{\circ} \mathrm{C}$ for cutting speeds of 1,2 and $4 \mathrm{~m} \mathrm{~s}^{-1}$, respectively. The affected depth also decreases similarly with the cutting speed. The temperature profiles in the vicinity of the cutting tool (i.e. $3 \mathrm{~mm}$ behind the laser spot) are shown in Fig. 10 for the three cutting speeds. It can be seen that the average temperatures in the layer of material removed are 377, 259 and $171{ }^{\circ} \mathrm{C}$ for the different cutting speeds. These temperatures cause a decrease in the cutting force of $34 \%, 21 \%$ and $10 \%$ with respect to conventional machining. This observation joins the results of the Shvarenina et al. which show a significant fall in temperature between the impact of the laser and the cutting tool [5].

The depth of the heated zone is greater than the cutting depth (i.e. $0.1 \mathrm{~mm}$ in Fig. 10). Therefore, some of the thermal energy provided by the laser is removed by machining. This heat energy which causes a global increase in the temperature of the workpiece, results in unwanted thermal expansion. This was observed experimentally.

\subsection{Comments on chip formation in LAM}

Differences, in terms of the temperature, stress and strain fields, can be observed when comparing the numerical simulation of conventional cutting and the simulation of LAM. Hence, various comments can be made concerning chip formation in LAM. Below, two simulations are compared with a cutting speed of $1 \mathrm{~m} / \mathrm{s}$ and a cutting depth of $0.1 \mathrm{~mm}$, with and without laser assistance of $1000 \mathrm{~W}$.

\subsection{Comparison of the primary shear zones}

The results show that the shear angle in the primary shear zone is approximately $35^{\circ}$ for conventional turning and only $21^{\circ}$ for LAM. This confirms the results of Lesourd [3] who stated that the shear angle decreases with an increase in the initial temperature of the workpiece. However, the decrease of the shear angle has the consequence of increasing the length of the primary shear zone and of increasing the thickness of the chip (Fig. 11).

The initial temperature, at the beginning of the primary shear zone is $20^{\circ} \mathrm{C}$ in the conventional turning case and approximately $380{ }^{\circ} \mathrm{C}$ for the LAM case. The large plastic deformation in this zone increases these temperature values to 300 and $600{ }^{\circ} \mathrm{C}$, respectively. Hence, the increase in temperature in the primary shear zone is more important in conventional machining than in LAM (respectively, 280 and $220^{\circ} \mathrm{C}$ ). 
Also, by comparing the thermal flux generated by the primary zone (i.e. self-heating) with and without laser assistance, the flux in conventional cutting is seen to be more significant. The average

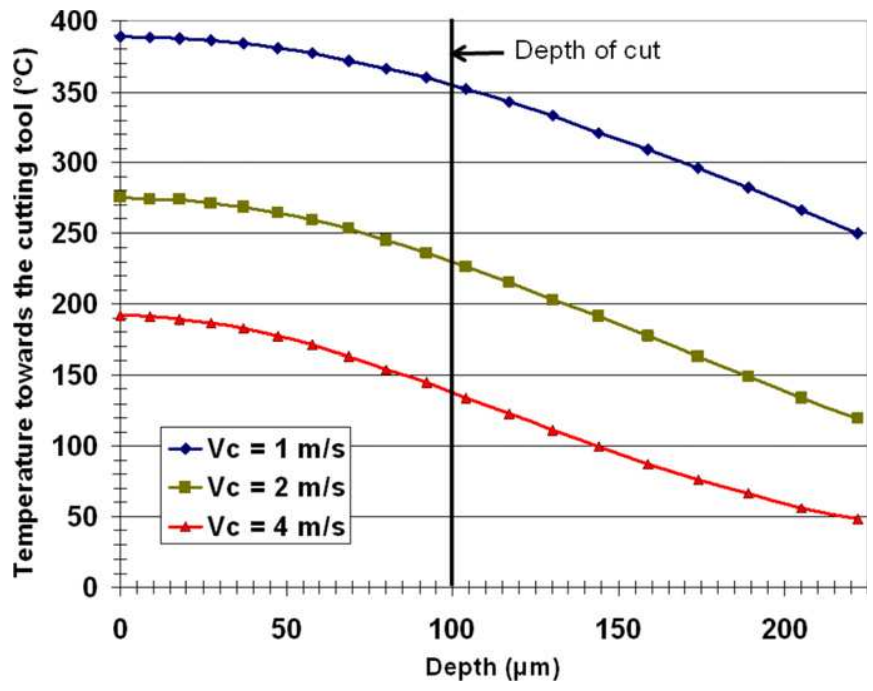

Fig. 10. Temperature profiles at the cutting tool for different cutting speeds. thermal flux in conventional turning is approximately $2.4 \times$ $10^{8} \mathrm{Wm}^{3}$ and only $1.7 \times 10^{8} \mathrm{Wm}^{3}$ in LAM (Fig. 12). This can be explained by the fact that the increase of temperature via the laser input results in a decrease in the flow stress which in turn causes less self-heating of the material during the plastic deformation.

\subsection{Comparison of the secondary shear zone (chip/tool)}

The chip temperature is strongly influenced by the friction between the tool and chip. The temperature at the tool/chip contact surfaces is calculated to be approximately $600{ }^{\circ} \mathrm{C}$ in conventional machining and $800{ }^{\circ} \mathrm{C}$ in LAM.

The heat generated by friction is proportional to the shear stress multiplied by the slip speed. The contact shear stress at the tool/ chip interface is approximately $100 \mathrm{MPa}$ in conventional machining and $77 \mathrm{MPa}$ in LAM. Also, the slip speed is slower in LAM due to the decrease of the shear stress angle. The slip speeds between the chip and tool have been calculated to be approximately $1.16 \mathrm{~m} \mathrm{~s}^{-1}$ in conventional machining and approximately $1.12 \mathrm{~m} \mathrm{~s}^{-1}$ in LAM. Hence, as the flow stress and the slip speed are lower in LAM, there is less heat generated. This is a positive point in favour of LAM, because an increase in temperature of approximately $400{ }^{\circ} \mathrm{C}$ of the workpiece causes only an increase of $200{ }^{\circ} \mathrm{C}$ at the tool (Fig. 11). The tool is less mechanically loaded in LAM as the stress at the contact surface between the tool and the workpiece remains low.

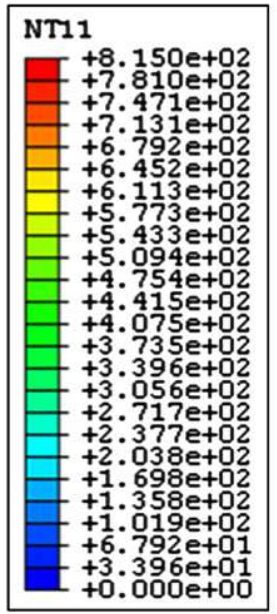

a
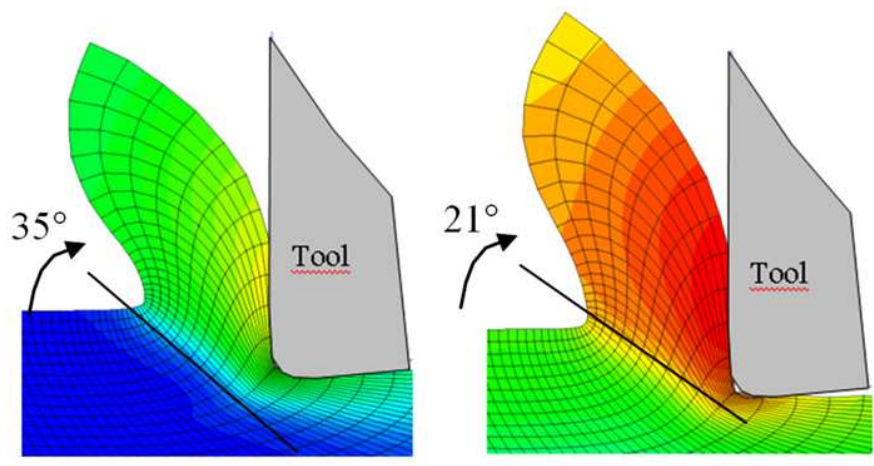

Fig. 11. Calculated temperature distribution (a) without and (b) with laser assistance.

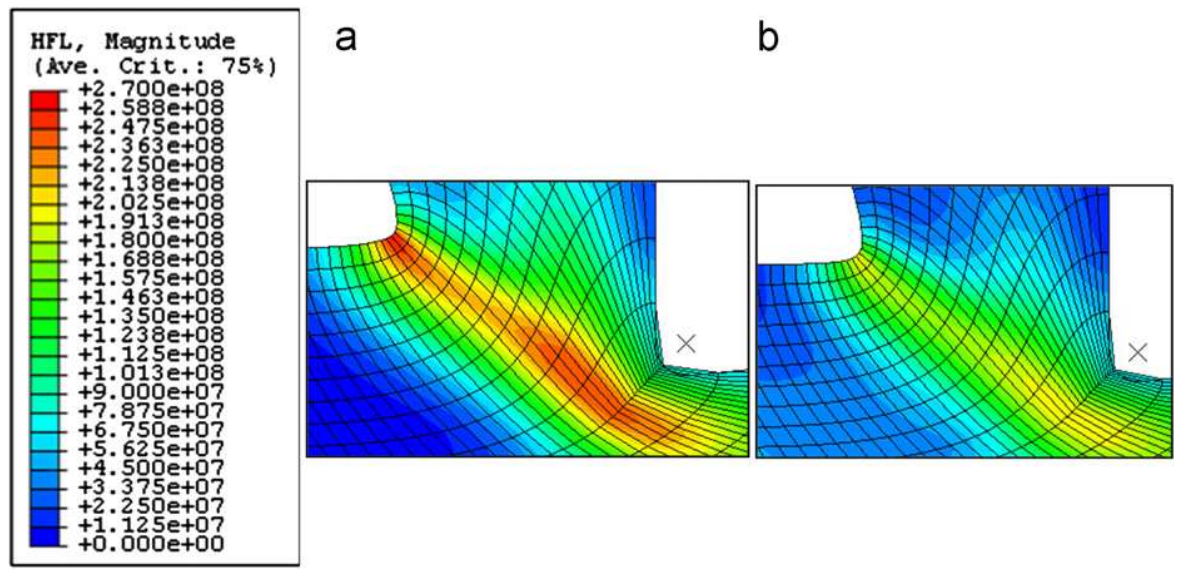

Fig. 12. Thermal flux distribution generated by the primary shear zone (a) without and (b) with laser assistance. 
a

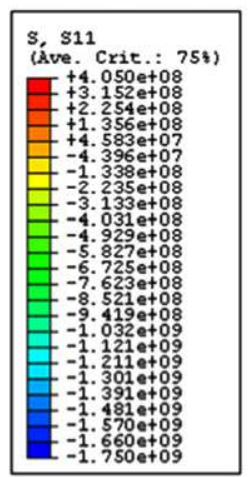

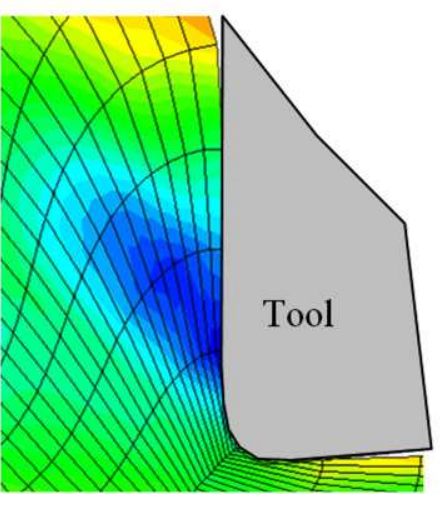

b

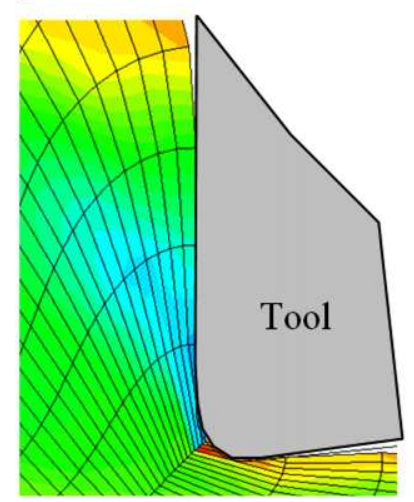

Fig. 13. Stress field in the secondary shear zone (a) without and (b) with laser assistance.

a

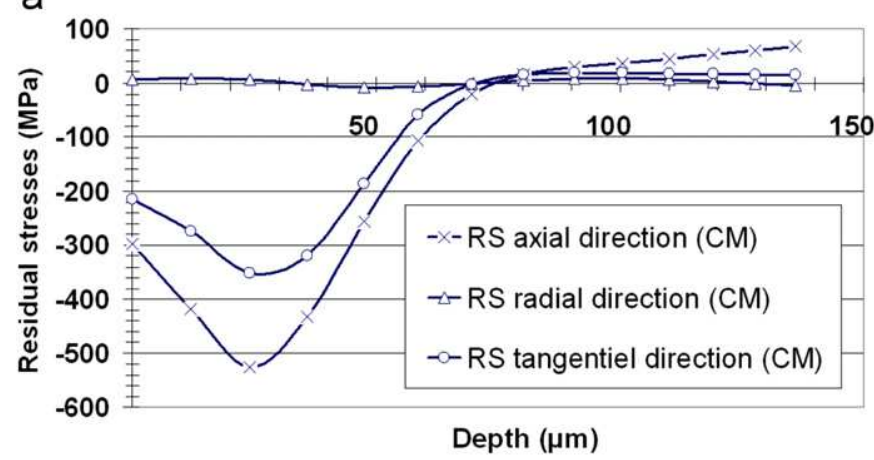

b

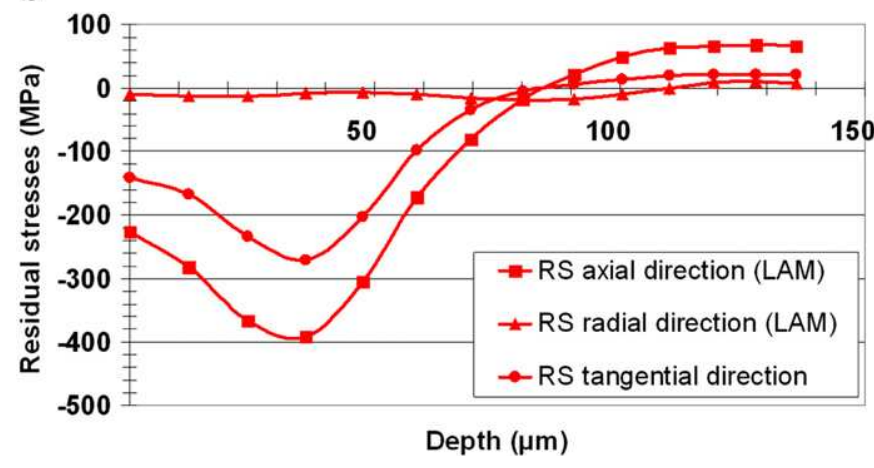

Fig. 14. Residual stress profiles for (a) conventional machining and (b) LAM.

In conventional machining on the other hand, there exists a strong compressive stress field $(-1750 \mathrm{MPa})$ normal to the contact surface between the tool and the workpiece. This zone also exists in LAM, however, the stress values are less important ( $-1300 \mathrm{MPa})$. The compressive zone of the chip on the tool is situated behind the cutting edge (Fig. 13). Lower stress in this zone could explain the decrease of the cutting force measured in LAM.

\subsection{Comparison of the tertiary zone (workpiece/tool)}

Even thought the tertiary shear zone is smaller in size, it has a strong influence on the surface integrity of the workpiece and in particular on the creation of residual stresses. Via the numerical simulations it was possible to calculate the depth of the zone affected by residual stresses and the residual stress profiles. The calculated profiles are in agreement with the experimentally determined profiles generally obtained in machining. Indeed, machining induces a residual stress profile that can be divided into three zones:

- A sharp increase in compressive residual stress within several tens of micrometers to a minimum value.

- Followed by a sharp increase of residual stress within several tens of micrometers up to the values of initial stress of the material.

- Then in order that the residual stress field is self-equilibrated, the stress slowly increases to a value slightly above the initial stress.

The results indicate that LAM causes lower compressive residual stress at the machined surface. A difference of $100-150 \mathrm{MPa}$ is observed between the numerically determined stress profiles in (a) conventional machining and (b) LAM (Fig. 14). This evolution of residual stresses is in accordance with experimental results observed in conventional and laser assisted machining on a titanium alloy [4].

\section{Conclusion}

Numerical simulations of conventional turning and LAM have been undertaken and validated against experimental tests. These experimental tests consisted of orthogonal turning of $42 \mathrm{CrMo}_{4}$ steel. Three cutting speeds were investigated $\left(1,2\right.$ and $\left.4 \mathrm{~m} \mathrm{~s}^{-1}\right)$ with a constant feed of $0.1 \mathrm{~mm}^{-\mathrm{rev}^{-1}}$. Each test was undertaken without laser assistance (Conventional Machining or CM) and with a laser assistance of $1000 \mathrm{~W}$.

The results show that:

(1) The numerical prediction of the tangential component of the cutting force is very good, with errors of less than $2 \%$ for CM and less than $8 \%$ for LAM compared to experimental tests.

(2) A reduction of the cutting force with laser assistance that is more pronounced with lower cutting speeds. The experimental tests showed a decrease in the cutting force in LAM with respect to $\mathrm{CM}$ of $34 \%, 21 \%$ and $10 \%$, for the 3 cutting speeds.

(3) A decrease in the heated depth and a decrease of the surface temperature with an increase in cutting speed. Indeed, the average temperature just in front of the cutting tool in the material being removed, for the 3 cutting speeds are 377, 259 and $171{ }^{\circ} \mathrm{C}$ 
Comparison of chip formation in the numerical analysis was also undertaken in both LAM and CM. This was done for simulations with a cutting speed of $1 \mathrm{~m} \mathrm{~s}^{-1}$ and a feed of $0.1 \mathrm{~mm} \cdot \mathrm{rev}^{-1}$.

The results show that:

(1) In LAM the average temperature in the primary shear zone (ZI) is approximately $400{ }^{\circ} \mathrm{C}$ higher than the corresponding temperature in $\mathrm{CM}$. Also, the stresses in the zone $\mathrm{ZI}$ are lower in LAM ( $\sim 1100 \mathrm{MPa})$ than in CM $(\sim 1700 \mathrm{MPa})$. This implies that in LAM the self-heating, due to the deformation, is less important in this zone, when compared to CM. The temperature difference between LAM and CM at the exit of the primary shear zone is less than $300{ }^{\circ} \mathrm{C}$.

(2) In the secondary shear zone (ZII) at the tool/chip interface, in LAM less heat is produced via friction between the tool and the chip. The temperature difference at the cutting face of the tool is not greater than $200{ }^{\circ} \mathrm{C}$. Less heat is generated in LAM because the shear stresses in the zone (ZII) are lower. Furthermore, the slip speed at the chip/tool interface is slower. The reason is that in LAM the shear angle in the $\mathrm{Z1}$ zone decreases. This increases the thickness of the chip and therefore decreases its sliding velocity. Moreover, the high compressive stresses located at the ZII zone are more important in $\mathrm{CM}(\sim 1700 \mathrm{MPa})$ compared to LAM $(\sim 1100 \mathrm{MPa})$.

To validate the thermal aspects of the numerical simulations, a new acquisition system is currently being developed to measure the temperature field. A near infra-red camera, directly fixed on the laser head support, will make it possible to analyze the thermal fields during a machining operation. With this set-up it will be possible to validate the thermal aspects of the numerical simulations in addition to the mechanical aspect. This acquisition system was developed by M'Saoubi [20] for conventional machining and it has recently enabled us to study the machining temperatures for treated bearing steel $100 \mathrm{Cr} 6$ at $55 \mathrm{HRc}$ [21].

\section{Acknowledgements}

This study has been carried out in the framework of a Contrat Plan Etat Région (CPER) Pays de la Loire gathering ECN, ENSAM Angers and CETIM.

\section{References}

[1] G.S. Kainth, B.K. Dey, Experimental investigation into tool life and temperature during hot machining of EN-24 steels, Bulletin Cercle Etudes des Métaux 14 (11) (1980) 22.1-22.7.

[2] T. Kitagawa, K. Katsuhiro, A. Kudo, Plasma hot machining for high hardness metals, Bulletin Japan Society of Precision Engineering 22 (2) (1988) 145-151.
[3] B. Lesourd, Etude et modélisation des mécanismes de formation de bandes de cisaillement intense en coupe des métaux. Application au tournage assisté laser de l'alliage de titane TA6V, Thesis, 1996, Ecole Centrale de Nantes.

[4] G. Germain, F. Morel, J.-L. Lebrun, A. Morel, B. Huneau, Effect of laser assistance machining on residual stress and fatigue strength for a bearing steel $(100 \mathrm{Cr} 6)$ and a titanium alloy (Ti6Al4V), Materials Science Forum 524-525 (2006) 559-574.

[5] M. Anderson, R. Patwa, Y.C. Shin, Laser-assisted machining of Inconel 718 with an economic analysis, International Journal of Machine Tools \& Manufacture 46 (2006) 1879-1891.

[6] S. Skvarenina, Y.C. Shin, Laser-assisted machining of compacted graphite iron, International Journal of Machine Tools \& Manufacture 46 (2006) 7-17.

[7] P. Dumitrescu, P. Koshy, J. Stenekes, M.A. Elbestawi, High-power diode laser assisted hard turning of AISI D2 tool steel, International Journal of Machine Tools \& Manufacture 46 (2006) 2006-2016.

[8] Y. Wang, L.J. Yang, N.J. Wang, An investigation of laser-assisted machining of $\mathrm{Al}_{2} \mathrm{O}_{3}$ particles reinforced aluminum matrix composite, Materials Processing Technologies 129 (2002) 268-272.

[9] F.E. Pfefferkorn, F.P. Incropera, Y.C. Shin, Heat transfer model of semitransparent ceramics undergoing laser-assisted machining", International Journal of Heat and Mass Transfer 48 (2005) 1999-2012.

[10] P.A. Rebro, Y.C. Shin, F.P. Incropera, Design of operating conditions for crackfree laser-assisted machining of mullite ceramic, International Journal of Machine Tools \& Manufacture 44 (2004) 667-694.

111] C.W. Chang, C.P. Kuo, Evaluation of surface roughness in laser-assisted machining of aluminum oxide ceramics with Taguchi method, International Journal of Machine Tools \& Manufacture 47 (2007) 141-147.

[12] G. Germain, J.-L. Lebrun, P. Robert, P. Dal Santo, A. Poitou, Experimental and numerical approaches of Laser assisted turning, International Journal of Forming Processes 8 (2005) 347-361.

[13] Q.H. Chen, Optimisation des caractéristiques métallurgiques et géométriques des zones superficielles de pièces traitées par laser : Modélisation et étude expérimentale, Thesis, ISAL82, 1995, Institut National des Sciences Appliquées de Lyon.

[14] J.C. Rozzi, F.E. Pfefferkorn, F.P. Incropera, Y.C. Shin, Transient thermal response of a rotating cylindrical silicon nitride workpiece subjected to a translating laser heat source: II. Parametric effects and assessment of a simplified model, ASME Journal of Heat Transfer 120 (1998) 899-906.

[15] J.C. Rozzi, F.E. Pfefferkorn, F.P. Incropera, Y.C. Shin, Transient three-dimensional heat transfer model for the laser assisted machining of silicon nitride: I. Comparison of predictions with measured surface temperature histories, International Journal of Heat and Mass Transfer 43 (8) (2000) 1409-1424.

[16] J.C. Rozzi, F.P. Incropera, Y.C. Shin, Transient, three-dimensional heat transfer model for the laser assisted machining of silicon nitride: II. Assessment of parametric effects, International Journal of Heat and Mass Transfer 43 (8) (2000) 1425-1437

[17] J.C. Rozzi, F.P. Incropera, Y.C. Shin, Transient thermal response of a rotating cylindrical silicon nitride workpiece subjected to a translating laser heat source: I. Comparison of surface temperature measurement with theoretical results, ASME Journal of Heat Transfer 120 (1998) 907-915.

[18] R. Heiple, Mechanism for minor element effect on GTA fusion zone geometry, Welding Journal, Welding Research Supplement (1982) 97-102.

[19] G.R. Johnson, W.H. Cook, A constitutive model and data for metals subjected to large strains, high strain rates and high temperatures, 7th International Symposium on Ballistics (1983) 541-547.

[20] R. M'Saoubi, Aspects thermiques et microstructuraux de la coupe-Application à la coupe orthogonale des aciers austénitiques, thesis, no 1998-09, ENSAM, 1998.

[21] M. Habak, J.-L. Lebrun, B. Huneau, G. Germain, P. Robert, Effect of carbides and cutting parameters on chip morphology and cutting temperature during orthogonal hard turning of $100 \mathrm{Cr}_{6}$ bearing steel with a cBN cutting tool, 9th CIRP International Workshop on Modeling of Machining Operations, 2006. 